\title{
Erratum to: A fully discretised polynomial approximation on spherical shells
}

\section{Yoshihito Kazashi ${ }^{1}$}

Published online: 20 July 2016

(C) Springer-Verlag Berlin Heidelberg 2016

\section{Erratum to: Int J Geomath DOI 10.1007/s13137-016-0084-1}

In this article, the equations $6.27 / 6.28$ should be

$$
\begin{aligned}
\left|f(x)-I_{M} f(x)\right| & =\left|\sum_{j=M+1}^{\infty} a_{j} T_{j}^{*}(x)-\sum_{k \in \mathcal{I}(M)} a_{k} T_{|v(k, M)|}^{*}(x)\right| \\
& \leq \sum_{k=M+1}^{\infty} 2\left|a_{k}\right| .
\end{aligned}
$$

The online version of the original article can be found under doi:10.1007/s13137-016-0084-1.

$凶$ Yoshihito Kazashi

y.kazashi@unsw.edu.au

1 School of Mathematics and Statistics, University of New South Wales, Sydney 2052, Australia 